TRANS FAMILY EDUCATION EVALUTION

A mixed methods evaluation of a gender affirmative education program for families of trans young people

Sharek, D., McCann, E., and Huntley-Moore, S.

Trinity College Dublin, School of Nursing \& Midwifery, 24 D’Olier Street Correspondence concerning this article should be addressed to Danika Sharek at sharekd@tcd.ie or 0872187872.

\title{
Funding
}

This work was supported by the Irish Research Council under Grant GOIPG/2015/1723.

\section{Disclosure statement}

The authors declare no conflicts of interest. 
TRANS FAMILY EDUCATION EVALUTION

Abstract

Research evidence suggests that education can play an important role in a family's acceptance and support of a trans(gender) young person. However, there is a lack of robust evidence around the impact of education programs for these families. This article reports the findings of a mixed methods evaluation of an online education program developed for families of trans young people. Surveys were administered before and after participation in the education program to assess the impact of the program on several measures, including trans-related knowledge, self-reflection and insight, family problem-solving, family communication, selfefficacy, and views of gender identity. Interviews were used to explore family members' experiences of the program, its perceived impact, and recommendations for further development. The survey findings revealed a statistically significant increase in knowledge scores from the pre-education program to post-education program. Interview participants felt the education program was accessible and easy-to-use and the majority reported learning about trans-related issues from the program. Fewer participants reported developing skills around self-reflection, problem-solving, and communication following participation in the program. The findings from this evaluation add to the evidence base concerning the efficacy of education for families of trans young people, with further implications and recommendations highlighted. Keywords: education, evaluation, family, intervention, mixed methods, transgender 
TRANS FAMILY EDUCATION EVALUTION

\section{A mixed methods evaluation of a gender affirmative education program for families of}

\section{trans young people}

Research has shown that education can help families accept and support a trans family member. However, there is a paucity of evidence around the development and evaluation of education programs aimed to support these families. This article aims to augment this gap by presenting the findings of a mixed methods evaluation of an online education program developed for families of trans young people in the Republic of Ireland.

\section{Literature Review}

There is a growing body of evidence on the experiences of young people who identify as trans(gender), however, a gap exists in how best to support their families. Parents, in particular, may experience difficult emotions such as shock, confusion, grief, and a sense of loss when learning their child is trans (Gregor, Hingley-Jones, \& Davidson, 2015). Parents may also feel they lack information to manage their own reactions and their trans child's experiences, with many parents reporting being uniformed about trans issues at the time of learning their child is trans (Field \& Mattson, 2016; Hegedus, 2009; Pearlman, 2006). This paucity of information for parents can contribute to challenging emotional responses they may experience when learning a child is trans (Field \& Mattson, 2016; Kuvalanka, Weiner, \& Mahan, 2014). While a lack of information may hinder families' ability to understand and accept a trans family member, accessing information and learning about trans identities is associated with facilitating the processes of adjustment within a family, helping them move towards acceptance (Gold, 2008; Guditis, 2009; Hill \& Menvielle, 2009; Pearlman, 2006). Families may use various strategies to access information, sourcing material from the internet, the trans family member, and the LGBT community and events (Gray, Sweeney, Randazzo, \& Levitt, 2016; Ishii, 2017; Pyne, 2016; Wren, 2002). A number of studies have identified support groups consisting of families of trans children and young people as an important source of 
TRANS FAMILY EDUCATION EVALUTION

support and information for families (Gray et al., 2016; Ishii, 2017; Kuvalanka et al., 2014; Pearlman, 2006).

Information and education may also help parents and families to develop appropriate ways of supporting their trans family member (Johnson \& Benson, 2014; Pearlman, 2006). Furthermore, trans-related education and information may provide some families with the requisite knowledge and confidence to enable them to advocate for their trans family member (Gray et al., 2016; Menvielle \& Hill, 2010; Rahilly, 2015). Such advocacy may take place within the wider family, with healthcare and education professionals, as well as within the wider community and society. A supportive family environment can make a positive contribution to the wellbeing of trans young people, including the development of resilience, enhanced self-esteem, and better general health (Ryan, Russell, Huebner, Diaz, \& Sanchez, 2010; Simons, Schrager, Clark, Belzer, \& Olson, 2013; Travers et al., 2012).

Within the international context, the need for rigorous and robust education and information resources for families is clear. The evidence which has emerged from other areas, including mental health (Barak, Hen, Boniel-Nissim, \& Shapira, 2008; Taylor-Rodgers \& Batterham, 2014; Ybarra \& Eaton, 2005), family support following traumatic brain injury (Wade, Carey, \& Wolfe, 2006), and parent training (Breitenstein, Gross, \& Christophersen, 2014; Enebrink, Hogstrom, Forster, \& Ghaderi, 2012) supports the efficacy of online learning, substantiating a need for its further investigation within the area of education for families of trans young people. However, there remains a distant lack of relevant online programs to support families of trans young people (Sharek, Huntley-Moore, \& McCann, 2018). To address this gap in resources, an online education program, GenderEd.ie, was developed as part of a larger study. 
TRANS FAMILY EDUCATION EVALUTION

\section{The online education program}

The goal of GenderEd.ie is to provide trans-related information to families of trans young people. By doing so, the program aims to enable family members of trans young people to identify and discuss key issues related to their trans family member and being a family member of a trans person. It also encourages family members to reflect on their own, as well as their family's experiences. Furthermore, the program aims to support family members of trans young people to communicate within the family about issues related to being and having a trans family member. Finally, the program focuses on helping families to address any challenges they may be facing and to know where to access additional supports and further information.

The program consists of eight learning modules. The first module provides introductory information related to gender identity and associated concepts, including language and terminology. The second module explores the experiences of families with a trans family member and aims to help family members reflect on their own experiences and how they can access support. In the next module, issues specifically related to the life stages of pre-pubescent children and adolescents are examined. The module on social transitioning explores the ways in which some trans young people may begin to express their gender identity socially, including around the use of names/pronouns, changing appearances, and in their social life. The fifth module examines issues related to health and wellbeing for trans children and young people and provides guidance around how to navigate the Irish healthcare system. In the following module, topics related to education settings for gender nonconforming and gender variant children and trans adolescents are considered. The seventh module provides guidance to families about how to navigate the legal and administrative system for trans young people. The final module looks at future expectations for trans young people and their family, highlighting that trans young people and their families, like all young people and their families, may have diverse life experiences. 
TRANS FAMILY EDUCATION EVALUTION

The module content and teaching strategies includes text, videos, personal stories, activities, and information about where to access further information and support. All program content is informed by the gender affirmative theory, which asserts that gender identity may be fluid and diverse, that gender development is complex, and that this is a natural, nonpathological, phenomenon (Hidalgo et al., 2013). Further information about the program and each individual module is available online at www.GenderEd.ie.

GenderEd.ie was developed in the Republic of Ireland through a participatory design which included collaboration with professionals, families of trans young people, and trans young people themselves. The design and development process included both a survey and interview consultation with these key stakeholder groups to identify the education needs of families of trans young people. Following this, program content was drafted and a survey evaluation was used to gather their view on this drafted program. This process informed the final program design. Professionals, families, and trans young people also participated in the creation of the program by writing stories for the website and participating in informational videos.

This paper reports on the outcomes of the evaluation of GenderEd.ie, which was part of a larger multiphase study that explored and addressed the education needs of families of trans young people.

\section{Methods}

\section{Study design}

The evaluation was comprised of a convergent parallel design in which qualitative and quantitative data were collected and analysed independently, then the results were compared and contrasted (Creswell, 2014). The quantitative strand used surveys to assess the extent of change in families' responses on a number of measures related to the education program goals. The qualitative strand used interviews to explore families' experiences with the program and to highlight recommendations for improving the program. 
TRANS FAMILY EDUCATION EVALUTION

\section{Data collection methods}

Surveys. The evaluation survey assessed participants on a number of measures related to the program goals directly before and after their participation in the education program. The survey included six sections:

1. demographic information;

2. self-rated knowledge on 14 trans-related topics;

3. the 20-item Self-Reflection and Insight Scale (Grant, Franklin, \& Langford, 2002);

4. the 11-item Family Problem Solving and Family Communication sub-scales of the McMaster Family Assessment Device (Epstein, Baldwin, \& Bishop, 1983);

5. the 10-item Generalised Self-Efficacy Scale (Schwarzer \& Jerusalem, 1995); and

6. 12 statements about views of gender identity developed from the gender affirmative theory and model by Hidalgo et al. (2013).

The post-education program survey included an additional five questions on the usefulness of the program, whether participants would recommend the program, how much of the program and activities they completed, and whether they kept a journal as part of the education program. Surveys were collected via an online survey tool (SurveyMonkey Inc., 2017) and all data were transferred into SPSS Statistics 24.0 (IBM Corp., 2016). Descriptive and inferential statistics were calculated. Inferential testing was used to explore relationships between variables, including independent samples t-tests (and non-parametric equivalent Mann-Whitney U tests) and paired-samples t-tests (and non-parametric equivalent Wilcoxon signed-ranked test).

Interviews. The qualitative interview schedule that was devised specifically for the study explored: participants' experiences of the education program; their views on the program, its content, and its perceived impact; and recommendations for developing the education program. In-depth, semi-structured telephone interviews were used to collect data (Rubin and Rubin 2012). All qualitative interview data were analyzed using a six-step process for inductive, 
TRANS FAMILY EDUCATION EVALUTION

semantic, thematic analysis (Braun \& Clarke, 2006). NVivo Version 9 (QSR International Pty Ltd., 2010) was used to store and manage qualitative data.

Sampling and recruitment. Non-probability convenience sampling was used to recruit. Any family member of a trans young person (aged 17 years and under) living in the study country was eligible to participate. The recruitment strategy included advertisements in family support groups, radio, television, and social media. Family members were invited to contact the researcher directly to participate in an interview. They could access the survey either through the GenderEd.ie website or directly through the SurveyMonkey link. Upon completing the pre-education program survey, participants were informed that they were being given three weeks to complete as much of the program as possible. They were advised that they should complete the post-survey as soon as possible after participating in the education program. After the three-week window for completing the program had passed, all participants who had completed the pre-survey, but had not yet completed the post-survey were sent email reminders inviting them to complete the post-survey. Two additional email reminders were sent. All participants who completed the survey were also invited to participate in the interviews by completing an 'opt-in' form.

Ethical considerations. Ethical approval to conduct the study was granted by the researchers' institution. There was also an acknowledgement of the ways in which the primary researcher's multiple identities may have played a role in the research, particularly as a cisgender researcher exploring trans issues (Galupo, 2017). A number of reflexive strategies were used to facilitate this examination, including reflexive diary keeping and exploring research relationships through dialogue with others, including colleagues, advisors, and study participants (Finlay \& Gough, 2003). 
TRANS FAMILY EDUCATION EVALUTION

\section{Results}

\section{Samples}

In total, eight participants completed both the pre- and post-education program surveys and eight family members participated in the telephone interviews. Of the eight survey respondents, seven also participated in the interviews, meaning that one participant participated in the interviews who had not also completed a survey.

\section{Survey}

Characteristics of respondents. Of the eight respondents who completed both the preeducation and post-education program surveys, the majority were parents of trans young people $(87.5 \% ; n=7)$, with one father $(12.5 \% ; n=1)$ and one brother $(12.5 \% ; n=1)$. The respondents' trans family members ranged in age from 9 to 17 years, with a mean age of 14.8 years $(\mathrm{SD}=2.9$ years). The trans family members had a range of gender identities, including: trans male $(50.0 \% ; n=4)$, trans female $(25.0 \% ; n=2)$, male $(12.5 \% ; n=1)$ and non-binary $(12.5 \% ; n=1)$. All of the respondents had known their family member was trans for more than seven months, with one respondent reporting they knew their child was trans "since he could communicate". The majority of respondents $(87.5 \% ; n=7)$ completed all eight modules of the program and completed some or all of the module activities.

Views on usefulness of education program. Respondents were asked to rate the usefulness of the program on a scale from zero 'not at all useful' to 10 'extremely useful'. The mean score given to the program was $8.6(\mathrm{SD}=2.2)$, with a range from four to 10 . Nearly $90 \%$ of the respondents reported that they would recommend the program to another family member of a trans young person, with one respondent reporting that they would 'maybe' recommend the program. Respondents were asked to explain their reasons for recommending the program, with five respondents provided additional information. Two mothers found the information particularly clear and relevant to their situation: "I found the information was presented in a 
TRANS FAMILY EDUCATION EVALUTION

clear way, and that the information was relevant" and "It covered all the important ground and answered questions I had".

One mother commented that the program was "very detailed and [included] a lot of extra resources", while a father remarked that "there is a wealth of useful practical advice - thanks!". Finally, another mother reported that the program "helped me make sense of what my child is going through".

Knowledge on gender identity. There was an increase in all scores on self-perceived knowledge of trans-related topics from pre-education program survey to post-education program survey. Over $75 \%$ of the sample reported that they were 'quite' or 'very' knowledgeable on nine of the 14 trans-related topics in the post-survey. All of the respondents felt they were quite or very knowledgeable on the differences between gender identity and sexual orientation, social issues for trans children and young people, and mental health issues for trans children and young people. When compared to the pre-program survey, all transrelated knowledge scores increased from pre- to post-education program survey, including the total score which increased from $47.4(S D=10.2)$ to $57.8(S D=9.3)$. Results from a pairedsamples t-test determined that respondents had significantly higher total trans-related knowledge scores post-program, a statistically significant increase of 10.4 points $(95 \% \mathrm{CI}, 5.5$ to 15.3 ) on the knowledge scale $[t(7)=5.03, p=.002]$. Inferential tests revealed statistically significant changes on six of the individual trans-related knowledge topics (indicated by the bold outlines in Figure 1). These included: social issues for trans children and young people; physical health issues for trans children and young people; educational issues for trans children and young people; issues related to the specific life stages of trans children and young people; the percentage of trans people in the Irish population; and legal issues related to trans children and young people nationally. 
TRANS FAMILY EDUCATION EVALUTION

Scores increased significantly from the pre-program survey to the post-program survey, with increases ranging 1.0 to 1.3 points.

\section{INSERT FIGURE 1 HERE}

Self-reflection and personal insight. There were no statistically significant differences on the Self-Reflection and Insight Scale from pre-education program survey $(M=8.0, S D=17.6)$ to post-education program survey $(M=77.1, S D=14.5)[t(6)=0.26, p=0.807]$.

Family communication and family problem-solving. Mean scores on the family communication sub-scale were identical from pre- $(M=2.0, S D=0.5)$ to post-program survey $(M=2.0, S D=0.5)$. Similarly, mean scores on the family problem-solving sub-scale remained steady from pre- $(M=1.9, S D=0.4)$ to post-program survey $(M=1.8, S D=0.4)$, with lower scores indicating improved family functioning. Neither of these differences were statistically significant $[t(7)=0.47, p=0.654$ and $t(7)=0.59, p=0.573]$.

Self-efficacy. Participant total self-efficacy scores were virtually identical from preprogram $(M=32.0, S D=3.5)$ to post-program $(M=31.6, S D=4.1)$. There were no statistically significant changes in the total self-efficacy score $[t(7)=0.38, p=0.714]$.

Views on gender identity. Scores on nine of the twelve gender affirmative statements increased from pre-education program survey to post-education program survey, indicating higher agreement with the gender affirmative statement. However, there were no statistically significant changes in any of the scores from pre- to post-program survey.

\section{Interviews}

Characteristics of participants. Eight family members participated in the interviews and all interview participants also completed the survey. Each participant was assigned a pseudonym, which was used throughout the findings. The characteristics of the interview participants are presented in Table 1.

\section{INSERT TABLE 1 HERE}


TRANS FAMILY EDUCATION EVALUTION

Five themes emerged from the analysis, including: (i) engagement with the education program; (ii) experiences of the website; (iii) views on the education program; (iv) perceived impact of the education program on participants; and (v) recommendations for developing the education program.

Engagement with the education program: "I was quite interested to see what new information I could get". Theme one described participants' engagement with the GenderEd.ie program. All of the participants learned about the education program through a major trans organisation and family support group in the country where the study was conducted. Participants cited various reasons for accessing the program. One participant said she felt "curiosity" about the program (Anne), while others were primarily focused on gaining information and educating themselves: "I was quite interested to see what new information I could get" (Kathleen). One participant wanted to "give back" to the trans organisation for supporting her and her daughter (Helen).

All of the participants reported engaging with the text-based content within the modules, and seven of the eight participants reported watching the informational videos. While none of the participants reported formally doing any of the activities included within the modules, some detailed different ways in which they engaged with the activities. One participant described how she used the activities as reflective exercises: "I kind of used it to reflect on, 'am I doing that?'” (Kathleen). Most of the participants indicated that they had already shared information about and recommended the program (or would in the future) with other family members, including their other children, partners, extended family, and the trans family member themselves. The majority of participants mentioned that they would also access the GenderEd.ie program again in the future.

Experiences of the website: "It was very user-friendly". The second theme encapsulated participants' experiences with using the GenderEd.ie website. Participants 
TRANS FAMILY EDUCATION EVALUTION

generally felt the program was easy-to-use, to navigate, and clearly laid out and agreed that it was "user-friendly" (Sandra and Kathleen), "clearly laid out" (Aoife), and "very easy to navigate" (Kathleen). Several participants spoke positively of the fact that the education program was available online, allowing participants to access it as often as they would like and at their own convenience: "You could dip in and out of it as well..." (Helen). Kathleen suggested that the program was also useful "for parents that can't get to a support group or something, to have another resource is brilliant".

Views on the education program: "It's just an amazing resource". In theme three, participants described how the program content was accessible and pitched at an appropriate level. They also perceived that it was comprehensive and relevant, without being burdensome. For example, Mary described the program as "so accessible and so informative", while Anne commented that "it's not too much over your head...it was just really like for parents". Participants described how the videos and personal stories included in the program helped personalize the information and make it more relatable to their own situation: "It's nice to have the personal...You know, that it's not just facts. It's people's families... what they've gone through, you know?" (Aoife). Kathleen described how she believed reading the personal stories could help families feel less alone: "You need to feel that you're not the only one that experiences this, you're not the only that struggles sometimes..." In general, participants felt the tone of the program was appropriate, and particularly appreciated the non-directive language and messages of reassurance.

Perceived impact of the education program on participants: "There's a lot of practical info there". In the fourth theme, the majority of participants reported that they learned new trans-related information from the program. However, the development of skills such as self-reflection, problem-solving, and communication were less evident in participants' discussions. One mother did describe how the program added to her sense of validation as a 
TRANS FAMILY EDUCATION EVALUTION

parent, while another suggested the program helped provide reassurance regarding her trans child and gave her greater confidence with trans issues. Several participants described the impact of the program on their views of gender identity and trans issues, with two participants specifically mentioning that the program helped "normalize" trans issues for them. Similarly, another participant described how the country-specific nature of the program helped make the information more accessible and relatable to their own context. Yvonne reported: "It [GenderEd.ie] just made it seem more mainstream, more normalized". Similarly, Anne described how reading the personal stories and seeing the videos "just normalizes it a bit" and makes you realise "it's happening in your own town...it's everywhere...it's kind of opening your eyes to it."

Key recommendations for developing the education program: "It was a good starting point". Theme five encapsulated participant recommendations for further developing the education program. Several participants suggested the development of additional areas of content, particularly involving siblings of trans young people. Some of the participants recommended that the program be more accessible to a greater number of people, advising development in other languages, the inclusion of a search/index function, and the provision of content tailored to individual user's needs. Many of the participants mentioned the importance of publicising and promoting the existence of GenderEd.ie, as well as ensuring its ongoing development, accessibility, and sustainability.

\section{Discussion}

\section{Opportunities for online education}

Interviews highlighted parents' beliefs that the online format of the education program contributed to its accessibility. Participants noted how such a format meant families could access and exit the program in their own time and in the privacy and convenience of a location of their choosing. Furthermore, as the internet was often the first port of call for trans-related 
TRANS FAMILY EDUCATION EVALUTION

information, it was perceived to be an appropriate place for an education resource. These findings concur with other international research that has underscored the importance of the internet as a resource for families of trans young people (Ishii, 2017; Katz-Wise et al., 2017; Kuvalanka et al., 2014; Rahilly, 2015). The benefits of online learning have been highlighted by other researchers who note its convenience, its flexibility to learners' needs, the potential for cost-effectiveness, and the opportunity to reach a wider audience (Kahn, 2005; Pugh, Chan, $\&$ Korol, 2015). It would be of interest for future research to quantify how many people are engaging with the program and how often and to what extent participants are engaging with it. It would also be of merit to explore the countries from which participants are accessing the program. While the program was designed specifically for those living in the Republic of Ireland, much of the content may have application and scope beyond that and it would be of relevance for researchers in other countries to consider how similar programs may be devised within their own localities.

\section{The need for family-wide education and information}

Parents, primarily mothers, comprised the majority of both the survey and interview samples. This high proportion of mother may be explained by research which has found that mothers may often take a primary role in supporting gender identity issues within the family, with fathers possibly experiencing greater challenges in accepting a trans child (Hill \& Menvielle, 2009; Kuvalanka et al., 2014; Riggs \& Due, 2015; Wren, 2002). This disproportionate representation of mothers has also been found in other international studies related to education for families of trans young people (Sharek et al., 2018). Within the interviews, parents emphasised the need for siblings of trans young people to have greater access to information and support. The experiences of siblings of trans young people has been explored in some studies (Cantner, 2012; Capous-Desyllas \& Barron, 2017; Gray et al., 2016; Guditis, 2009). However, the role of trans-related education and information in their lives has 
TRANS FAMILY EDUCATION EVALUTION

not been investigated to any great extent with one key exception. Kuvalanka et al. (2014) reported that siblings of trans young people benefited from information which helped siblings accept, understand, and advocate for their trans sibling. Within the current study, participants expressed a need for information for siblings, including younger siblings, about their brother or sister's trans identity. Parents also felt they needed accessible information in order to explain their trans child's identity to their other children. In addition, parents vocalised a need for younger siblings to have access to age-appropriate information, which they suggested might take the format of cartoons or animations. These findings offer a new dimension to the international literature, not only substantiating the need for education and information for siblings of trans young people, but also providing evidence of the types of education siblings of trans young people may require.

These findings, taken together with other international research, suggest that education should be targeted towards the family in its entirety, including mothers, fathers, and siblings. The findings likely reflect the idea that a young person's gender transition does not happen in a vacuum; instead, it happens typically within a family unit and a broader social context. The contextualised experience of a young person's transition is reflected by the family systems theory which emphasises that while independent, each member of the family has a powerful effect on the others (Bowen, 1993). Thus, it may be useful to target education towards each member of the family unit, as a change in one family member may have an influential effect within the whole family. Therefore, it is likely there is a need to take a family-focused approach to trans-related education. Within this context, it would be useful to extend any evaluation to include multiple members of the same family to explore their individual experiences with the program. 
TRANS FAMILY EDUCATION EVALUTION

\section{Impact of education program on family member participants}

Participants in the pre-education program survey rated their knowledge of trans-related topics as relatively low. These findings align with other international research evidence which found that families generally lacked understanding and familiarity with trans issues (Field \& Mattson, 2016; Pearlman, 2006; Riley, Sitharthan, Clemson, \& Diamond, 2013a; Wren, 2002). Both the evaluation survey and interview findings converged to suggest that the program impacted positively on parents' trans-related knowledge. In the future, it would be useful to conduct a more in-depth evaluation of participants' views on each of the modules to explore which topics they perceived as most and least useful in terms of gaining knowledge.

One of the key goals of the education program was to examine any impact on selfreflection and personal insight, as some studies have highlighted how having a trans family member may facilitate personal development and growth (Cantner, 2012; Gregor, 2013; Ishii, 2017; Pearlman, 2006; Wren, 2002). While there was no quantitative data to support the program's impact on personal reflection and insight, the qualitative interviews suggest the program may have provided some participants with a space for reflection.

Within the literature, communication between a trans young person and their family has been identified as important (Guditis, 2009; Pearlman, 2006; Rahilly, 2015; Wren, 2002). One of the aims of the education program was to enable families to communicate and discuss issues related to being or having a trans family member. No statistically significant changes were found on the survey in terms of communication. However, within the interviews there was evidence that participants were sharing information about GenderEd.ie with other family members. In the future, it is recommended that further research be undertaken to examine how trans-related communication within the family may be enhanced. This is especially important as trans young people have highlighted a need to be understood and respected which they have 
TRANS FAMILY EDUCATION EVALUTION

linked with the need to be listened to, heard, and affirmed (Riley, Clemson, Sitharthan, \& Diamond, 2013b).

Having a trans person within a family may present challenges for the family unit (Cantner, 2012; Gold, 2008; Hegedus, 2009; Sharek, 2018). An aim of GenderEd.ie was to enable families to address such challenges. However, neither the surveys nor the interviews revealed any impact of the program in terms of family problem-solving. Future research may consider how to enhance the impact of education and information resources on families' problem-solving skills, as conflict may arise within the family in relation to the family member's trans identity and between parents (Gold, 2008; Gray et al., 2016).

Trans-related education and information has been associated with increased confidence and enhanced advocacy amongst family members (Gray et al., 2016; Menvielle \& Hill, 2010; Wren, 2002). The education program aimed to enable families to address any trans-related challenges and to know where to access additional supports and further resources. While the surveys did not identify any significant changes in terms of self-efficacy, two of the interview participants illustrated how the program impacted on their sense of confidence, validating their parenting choices. Supporting these findings, education has been associated with a reduction in parents' anxiety (Hegedus, 2009) and confusion (Gregor et al., 2015), adding to a sense of their own empowerment (Cantner, 2012). Menvielle and Hill (2010) have highlighted similar benefits from a parent support group in the USA:

Provided a way for parents to double-check that their instincts were correct, or at least think through other ways of reacting and supporting their child...This validation helped this parent to feel more certain about parenting decisions as a result of the validation gained through the group: 'Anybody who tries to argue with us now, we just dig our heels in. It's like we're so sure we're on the right track' (Menvielle \& Hill, 2010, p.118). 
TRANS FAMILY EDUCATION EVALUTION

Within each module a set of skills-related activities was included to encourage participants to apply the information learned through the program to their own lives. Participants' level of engagement with the activities was generally low and the program was found to have had no statistical impact on participants' skills. The researchers have hypothesized that it may have been unreasonable to expect that all participants to access the program with the intention of completing the skills application component during their initial engagement. Furthermore, it was felt by some participants that the skills activities may have been most useful to family members who had recently learning they had a trans relative.

One of the aims of the evaluation was to explore whether the program had any impact on participants' views of gender identity. The survey revealed no statistically significant changes in participants' views. However, some interviews revealed the impact of the program in helping "normalize" trans issues. Participants also explained how the personal stories and information videos added a relatable element to the program, highlighting the ways in which they personally connected with the stories and videos.

In other studies, parents have identified their engagement in peer support groups as a factor in their normalization of trans identities (Cantner, 2012; Hegedus, 2009; Katz-Wise et al., 2017). For instance, in Ishii's (2017) interviews with Japanese mothers, one participant recalled the reassurance she felt after reading a story online about another mother who struggled to accept her lesbian daughter: "I knew the situation in which I was stuck was OK" (p.9). Of interest, these findings also mirror some of the positive benefits identified by families in accessing support from the LGBT community (Gray et al., 2016; Ishii, 2017; Pyne, 2016; Riley et al., 2013a). Within these studies, the families' interactions with the LGBT community were perceived as adding to families' sense of the relatability of trans people more generally. The findings of the current study, taken together with international research, suggest that 
TRANS FAMILY EDUCATION EVALUTION

information provision including a personal element may positively enhance a family member's views of gender identity.

\section{Education and information beyond the individual parent}

Survey and interview findings both confirmed that participating parents would recommend GenderEd.ie to other people both within and beyond the families of trans young people. While the program did not directly aim to impact on participants' advocacy skills, these findings suggest that the participating families are pro-actively information sharing. It may also be possible that the increases in knowledge associated with the program may contribute to an enhanced sense of confidence. This, in turn, may impact positively on a family member's ability to advocate for their trans family member (Gray et al., 2016; Menvielle \& Hill, 2010; Wren, 2002). Within the interviews, some participants discussed the potential usefulness of the education program for people such as educators and healthcare professionals in their interactions with young trans people, suggesting that healthcare and education professionals may be misinformed or uniformed about trans issues (Cantner, 2012; Johnson \& Benson, 2014; Pyne, 2016; Riley et al., 2013b; Sharek, 2018). These findings indicate that such education programs may have an audience beyond the families of trans young people.

\section{Future implications}

While GenderEd.ie targeted families of trans young people, the findings suggest that more widespread trans-related education is required for other groups, such as trans young people, their peers, siblings of trans young people (including younger siblings), educators, healthcare professionals, and the general public. It is also worth considering how to develop and expand GenderEd.ie to enhance participants' ability to successfully advocate for their trans family member in various areas, including within the family, and within education and healthcare settings. 
TRANS FAMILY EDUCATION EVALUTION

In the future, there may also be opportunities to employ more experimental designs and more rigorous measures to evaluate GenderEd.ie, including the use of behavioural observations or control groups to compare changes amongst samples (Cohen, Manion, \& Morrison, 2011; Vanderstoep \& Johnston, 2009). It would be important to ensure that such any experimental design takes into account ethical issues surrounding the use of a control group (Buchanan, Miller, \& Wallerstein, 2007). It would also be essential to consider strategies for increasing not only sample sizes, but also the diversity of participants in the evaluation.

\section{Strengths and limitations}

This is the first published evaluation to have provided rigorous evidence of the impact of an education program on families' trans-related knowledge (Sharek, 2018). This study also helps to address the paucity of mixed methods and quantitative research evidence available in the field (Bible, Bermea, van Eeden-Moorefield, Benson, \& Few-Demo, 2017). The study was limited by reliance on a non-probability convenience sample comprised of those most likely to be supportive of a trans family member, that is, mothers and people in support groups (Bible et al., 2017; Cohen et al., 2011; Sharek, 2018). The sample was also limited to those with access to the internet, basic technological literacy, and ability to read and comprehend English (Cohen et al., 2011; Fowler, 2014; Neuman, 2011). In addition, the survey samples were small, which at times impacted on the ability to carry out the most robust statistical testing available and may have made the findings vulnerable to Type 1 and Type 2 errors (Pallant, 2013). It is also important to note that the survey findings indicate correlation, not causation; however, the interview findings bolster and strengthen the survey findings by providing further qualitative data on the positive impact of the program. As this was an exploratory study, even with these limitations, it has provided useful findings with implications for the further development of the education program and for future research. 
TRANS FAMILY EDUCATION EVALUTION

\section{Conclusion}

GenderEd.ie was designed to address the information needs of families of trans young people. The results of the mixed methods evaluation indicate that the program achieved its purpose by positively impacting participants' trans-related knowledge. Furthermore, participants found the program to be easily accessible and useful and they would recommend it to other families of trans young people. However, scope remains to strengthen the program's impact in terms of supporting participants' self-reflection and developing and applying communication, and problem-solving skills. In conclusion, the evaluation has demonstrated that an education program has the potential to help positively support families and trans young people. 
TRANS FAMILY EDUCATION EVALUTION

\section{References}

Barak, A., Hen, L., Boniel-Nissim, M., \& Shapira, N. (2008). A comprehensive review and a meta-analysis of the effectiveness of internet-based psychotherapeutic interventions. Journal of Technology in Human Services, 26(2-4), 109-160. doi:10.1080/15228830802094429

Bible, J., Bermea, A., van Eeden-Moorefield, B., Benson, K. E., \& Few-Demo, A. L. (2017). A content analysis of the first decade of the Journal of GLBT Family Studies. Journal of GLBT Family Studies, 14(4), 337-355. doi:10.1080/1550428X.2017.1349626

Bowen, M. (1993). Family Therapy in Clinical Practice (1st ed.). Lanham, MD, USA: Rowman \& Littlefield Publishers, Inc.

Braun, V., \& Clarke, V. (2006). Using thematic analysis in psychology. Qualitative Research in Psychology, 3(2), 77-101.

Breitenstein, S. M., Gross, D., \& Christophersen, R. (2014). Digital delivery methods of parenting training interventions: A systematic review. Worldviews on Evidence-Based Nursing, 11(3), 168-176. doi:10.1111/wvn.12040

Buchanan, D. R., Miller, F. G., \& Wallerstein, N. (2007). Ethical issues in Community-Based Participatory Research: Balancing rigorous research with community participation in community intervention studies. Progress in Community Health Partnerships, 1(2), 153-160. doi:10.1353/cpr.2007.0006

Cantner, C. E. (2012). Loving Beyond Gender: Family Experiences of Transgender Loved Ones. (Doctor of Psychology Psy.D.), Long Island University, Brookville, NY, USA. ProQuest Dissertations \& Theses A\&I database.

Capous-Desyllas, M., \& Barron, C. (2017). Identifying and navigating social and institutional challenges of transgender children and families. Child and Adolescent Social Work Journal, 34(6), 527-542. doi:10.1007/s10560-017-0491-7 
TRANS FAMILY EDUCATION EVALUTION

Cohen, L. J., Manion, L., \& Morrison, K. (2011). Research Methods in Education. New York, NY, USA: Routledge.

Creswell, J. W. (2014). Research Design: Qualitative, Quantitative, and Mixed Methods Approaches (4th ed.). Thousand Oaks, CA, USA: Sage Publications, Inc.

Enebrink, P., Hogstrom, J., Forster, M., \& Ghaderi, A. (2012). Internet-based parent management training: a randomized controlled study. Behaviour Research \& Therapy, 50(4), 240-249. doi:10.1016/j.brat.2012.01.006

Epstein, N. B., Baldwin, L. M., \& Bishop, D. S. (1983). The McMaster Family Assessment Device. Journal of Marital and Family Therapy, 9(2), 171-180. doi:10.1111/j.17520606.1983.tb01497.x

Field, T. L., \& Mattson, G. (2016). Parenting transgender children in PFLAG. Journal of GLBT Family Studies, 12(5), 413-429. doi:10.1080/1550428x.2015.1099492

Finlay, L., \& Gough, B. (Eds.). (2003). Reflexivity: A practical guide for researchers in health and social sciences. Oxford, UK: Blackwell Publishing Ltd.

Fowler, F. J. (2014). Survey Research Methods (5th ed.). Thousand Oaks, CA, USA: Sage Publications, Inc.

Galupo, M. P. (2017). Researching while cisgender: Identity considerations for transgender research. International Journal of Transgenderism, 18(3), 241-242. doi:10.1080/15532739.2017.1342503

Gold, M. L. (2008). A Qualitative Investigation into the Process of Family Adjustment to Transgender Emergence. (Doctor of Psychology Psy.D.), Massachusetts School of Professional Psychology, Newton, MA, USA. ProQuest Dissertations \& Theses A\&I database. 
TRANS FAMILY EDUCATION EVALUTION

Grant, A. M., Franklin, J., \& Langford, P. (2002). The self-reflection and insight scale: A new measure of private self-consciousness. Social Behavior and Personality, 30(8), 821836. doi:10.2224/sbp.2002.30.8.821

Gray, S. A. O., Sweeney, K. K., Randazzo, R., \& Levitt, H. M. (2016). "Am I doing the right thing?": Pathways to parenting a gender variant child. Family Process, 55(1), 123-138. doi:10.1111/famp.12128

Gregor, C. (2013). How Might Parents of Pre-Pubescent Children with Gender Identity Issues Understand Their Experience? (Professional Doctorate in Social Work D.S.W.), University of East London, London, UK. ProQuest Dissertations \& Theses A\&I database.

Gregor, C., Hingley-Jones, H., \& Davidson, S. (2015). Understanding the experience of parents of pre-pubescent children with gender identity issues. Child and Adolescent Social Work Journal, 32(3), 237-246. doi:10.1007/s10560-014-0359-z

Guditis, L. C. (2009). When a Transsexual Family Member Transitions: A Qualitative Exploration of the Family's Experience. (Doctor of Philosophy), Texas Women's University, Denton, TX, USA. Sociology Collection database.

Hegedus, J. K. (2009). When a Daughter Becomes a Son: Parents' Acceptance of Their Transgender Children. (Doctor of Psychology), Alliant International University, San Francisco, CA, USA. Sociology Collection database.

Hidalgo, M. A., Ehrensaft, D., Tishelman, A. C., Clark, L. F., Garofalo, R., Rosenthal, S. M., ... Olson, J. (2013). The Gender Affirmative Model: What we know and what we aim to learn. Human Development, 56(5), 285-290. doi:10.1159/000355235

Hill, D. B., \& Menvielle, E. (2009). "You have to give them a place where they feel protected and safe and loved": The views of parents who have gender-variant children and 
TRANS FAMILY EDUCATION EVALUTION

adolescents. Journal of LGBT Youth, 6(2-3), 243-271. doi:10.1080/19361650903013527

IBM Corp. (2016). IBM SPSS Statistics for Windows, Version 24.0. Retrieved from Armonk, NY, USA:

Ishii, Y. (2017). Rebuilding relationships in a transgender family: The stories of parents of Japanese transgender children. Journal of GLBT Family Studies, 14(2), 213-237. doi:10.1080/1550428X.2017.1326015

Johnson, S. L., \& Benson, K. E. (2014). "It's always the mother's fault": Secondary stigma of mothering a transgender child. Journal of GLBT Family Studies, 10(1-2), 124-144. doi:10.1080/1550428X.2014.857236

Kahn, B. K. (2005). A comprehensive e-learning model. Journal of E-learning and Knowledge Society, 1(1), 33-44.

Katz-Wise, S. L., Budge, S. L., Fugate, E., Flanagan, K., Touloumtzis, C., Rood, B., . . . Leibowitz, S. (2017). Transactional pathways of transgender identity development in transgender and gender-nonconforming youth and caregiver perspectives from the Trans Youth Family Study. International Journal of Transgenderism, 18(3), 243-263. doi:10.1080/15532739.2017.1304312

Kuvalanka, K. A., Weiner, J. L., \& Mahan, D. (2014). Child, family, and community transformations: Findings from interviews with mothers of transgender girls. Journal of GLBT Family Studies, 10(4), 354-379. doi:10.1080/1550428X.2013.834529

Menvielle, E., \& Hill, D. B. (2010). An affirmative intervention for families with gendervariant children: A process evaluation. Journal of Gay \& Lesbian Mental Health, 15(1), 94-123. doi:10.1080/19359705.2011.530576

Neuman, W. L. (2011). Social Research Methods: Qualitative and Quantitative Approaches (7th ed.). Boston, MA, USA: Pearson Education, Inc. 
TRANS FAMILY EDUCATION EVALUTION

Pallant, J. (2013). SPSS Survival Manual (5th ed.). Berkshire, England, UK: Open University Press.

Pearlman, S. F. (2006). Terms of connection: Mother-talk about female-to-male transgender children. Journal of GLBT Family Studies, 2(3-4), 93-122. doi:10.1300/J461v02n03_06

Pugh, N., Chan, K. P., \& Korol, C. (2015). It takes a global village: Internet-delivered interventions supporting children and their families. In B. Kirkcaldy (Ed.), Promoting Psychological Wellbeing in Children and Families. London, UK: Palgrave Macmillan.

Pyne, J. (2016). "Parenting is not a job...it's a relationship": Recognition and relational knowledge among parents of gender non-conforming children. Journal of Progressive Human Services, 27(1), 21-48. doi:10.1080/10428232.2016.1108139

QSR International Pty Ltd. (2010). NVivo Qualitative Data Analysis Software, Version 9. Retrieved from

Rahilly, E. P. (2015). The gender binary meets the gender-variant child: Parents' negotiations with childhood gender variance. Gender \& Society, 29(3), 338-361. doi:10.1177/0891243214563069

Riggs, D. W., \& Due, C. (2015). Support experiences and attitudes of Australian parents of gender variant children. Journal of Child and Family Studies, 24(7), 1999-2007. doi:10.1007/s10826-014-9999-z

Riley, E. A., Clemson, L., Sitharthan, G., \& Diamond, M. (2013b). Surviving a gender-variant childhood: The views of transgender adults on the needs of gender-variant children and their parents. Journal of Sex and Marital Therapy, 39(3), 241-263. doi:10.1080/0092623X.2011.628439 
TRANS FAMILY EDUCATION EVALUTION

Riley, E. A., Sitharthan, G., Clemson, L., \& Diamond, M. (2013a). Recognising the needs of gender-variant children and their parents. Sex Education, 13(6), 644-659. doi:10.1080/14681811.2013.796287

Ryan, C., Russell, S. T., Huebner, D., Diaz, R., \& Sanchez, J. (2010). Family acceptance in adolescence and the health of LGBT young adults. Journal of Child and Adolescent Psychiatric Nursing, 23(4), 205-213. doi:10.1111/j.1744-6171.2010.00246.x

Schwarzer, R., \& Jerusalem, M. (1995). Generalized Self-Efficacy scale. In Measures in Health Psychology: A user's portfolio (pp. 35-37). Windsor, UK: NFER-NELSON.

Sharek, D. (2018). The Design, Development, and Evaluation of an Education Programme for Families of Trans Young People: A Community-Based Participatory Research Study. $(\mathrm{PhD})$, University of Dublin, Trinity College, Dublin, Ireland.

Sharek, D., Huntley-Moore, S., \& McCann, E. (2018). Education needs of families of transgender young people: A narrative review of international lierature. Issues in Mental Health Nursing, 39(1), 59-72. doi:10.1080/01612840.2017.1395500

Simons, L., Schrager, S. M., Clark, L. F., Belzer, M., \& Olson, J. (2013). Parental support and mental health among transgender adolescents. Journal of Adolescent Health, 53(6), 791-793. doi:10.1016/j.jadohealth.2013.07.019

SurveyMonkey Inc. (2017). www.surveymonkey.com. Retrieved from San Mateo, CA, USA:

Taylor-Rodgers, E., \& Batterham, P. J. (2014). Evaluation of an online psychoeducation intervention to promote mental health help seeking attitudes and intentions among young adults: Randomised controlled trial. Journal of Affective Disorders, 168, 65-71. doi:10.1016/j.jad.2014.06.047

Travers, R., Bauer, G., Pyne, J., Bradley, K., Gale, L., \& Papadimitriou, M. (2012). Impact of Strong Parental Support for Trans Youth. Retrieved from Ontario, Canada: 
TRANS FAMILY EDUCATION EVALUTION

Vanderstoep, S. W., \& Johnston, D. D. (2009). Research Methods for Everyday Life: Blending Qualitative and Quantitative Approaches. San Francisco, CA, USA: John Wiley \& Sons, Inc.

Wade, S. L., Carey, J., \& Wolfe, C. R. (2006). The efficacy of an online cognitive-behavioral family intervention in improving child behavior and social competence following pediatric brain injury. Rehabilitation Psychology, 51(3), 179-189. doi:10.1037/00905550.51 .3 .179

Wren, B. (2002). 'I can accept my child is transsexual but if I ever see him in a dress I'll hit him': Dilemmas in parenting a transgendered adolescent. Clinical Child Psychology and Psychiatry, 7(3), 377-397. doi:10.1177/1359104502007003006

Ybarra, M. L., \& Eaton, W. W. (2005). Internet-based mental health interventions. Mental Health Services Research, 7(2), 75-87. 
TRANS FAMILY EDUCATION EVALUTION 